\title{
Prediction of mortality and serious ventricular arrhythmia in hypertrophic cardiomyopathy An echocardiographic study
}

\author{
YOSHINORI L DOI, * WILLIAM J MCKENNA,† SIVABAKIYAM CHETTY, \\ CELIA M OAKLEY, JOHN F GOODWIN
}

From the Division of Cardiovascular Disease (Clinical Cardiology), Royal Postgraduate Medical School, Hammersmith Hospital, London

SUMMARY M-mode echocardiography was performed on 26 patients with clinical and angiographic hypertrophic cardiomyopathy to assess the echocardiographic prediction of serious ventricular arrhythmia. These patients had previously undergone 48-hour ambulatory electrocardiographic monitoring both on and off beta-adrenergic blocking drugs and were grouped according to the most serious ventricular arrhythmia detected: (A) ventricular tachycardia, eight patients; (B) multiform or paired ventricular extrasystoles, 11 patients; (C) uniform ventricular extrasystoles, seven patients. Septal amplitude of motion at chordal level and septal systolic thickening showed a significant difference between group A and C, and group B and C. Systolic anterior movement of the mitral valve and mid-systolic closure of the aortic valve were detected with identical frequency and were both seen in two patients $(25 \%)$ in group A, seven patients $(64 \%)$ in group $B$, and six patients $(86 \%)$ in group C. These echocardiographic features of obstruction were inversely correlated with ventricular tachycardia. Septal amplitude of motion was then assessed just below the mitral valve and at chordal level by continuous sweep recording and the pattern of septal motion was graded from normal (type I) to absent (type V) or as paradoxical (type VI). Six patients (75\%) in group A showed type IV, V, or VI; seven patients $(64 \%)$ in group B showed type III; and six patients $(86 \%)$ in group C showed type I or II. The patients with ventricular tachycardia were the patients with the most severely impaired pattern of septal motion.

Sudden death is the most important feature of the natural history of hypertrophic cardiomyopathy since it is often unexpected and is the commonest mode of death. ${ }^{1}$ The recent detection of a 50 per cent incidence of serious ventricular arrhythmia in an unselected series of patients with hypertrophic cardiomyopathy may have provided a valuable predictor of those patients at particular risk. ${ }^{2}$ No clinical or haemodynamic index predicted which of those patients would have ventricular tachycardia, and this is consistent with retrospective studies which have failed to identify predictive features for sudden death. ${ }^{3}$

Although not proven, patients with serious

* Recipient of a grant from the British Heart Foundation. Present address: The Third Division (Cardiology), Department of Medicine, Osaka Medical College, Takatsuki, Osaka 569, Japan.

t Research fellow of the Medical Research Council of Canada. Received for publication 28 December 1979 ventricular arrhythmia are likely to be at risk from sudden death. This study was undertaken to examine the $\mathrm{M}$-mode echocardiogram for features predictive of serious ventricular arrhythmia. In addition to the classical echocardiographic features, special attention has been focused on a continuous sweep recording from the base of the heart longitudinally toward the apex to assess amplitude of motion at different levels of the ventricular septum.

\section{Subjects and methods}

M-mode echocardiography was performed on 26 of 27 unselected patients with clinical and angiographic evidence of hypertrophic cardiomyopathy who had previously undergone 48 -hour outpatient ambulatory electrocardiographic monitoring both off and on beta-adrenergic blocking drugs. ${ }^{2}$ The echocardiography was performed one to nine months (mean: three months) from the ambulatory 


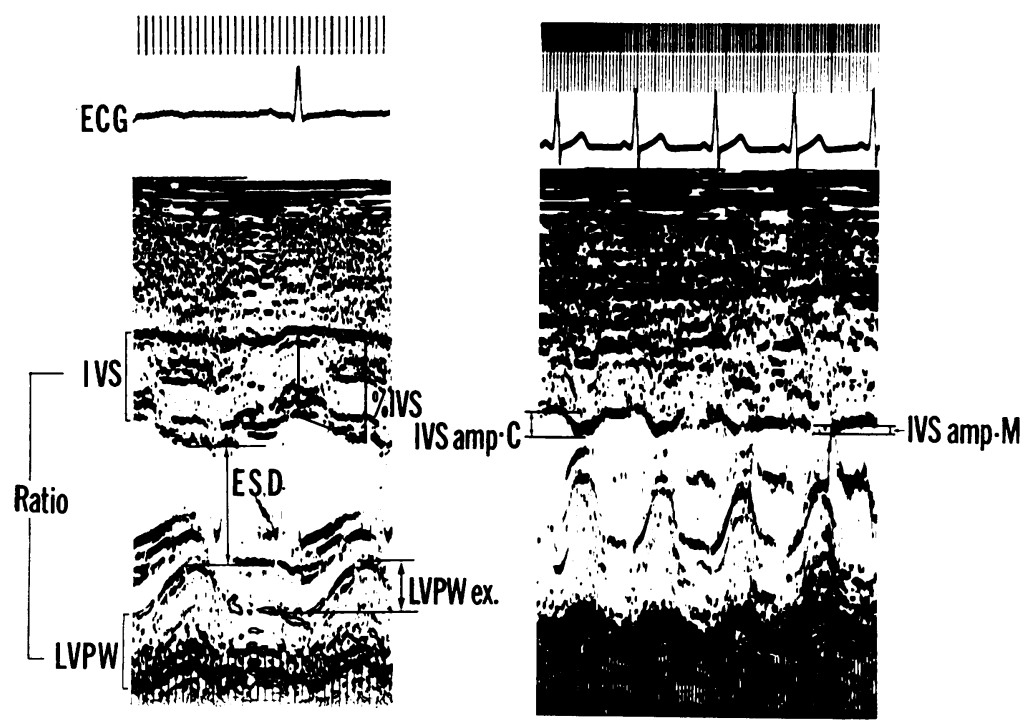

Fig. 1 The echocardiographic features assessed. ECG, electrocardiogram; IVS, ventricular septal thickness; Ratio, ventricular septal thickness to posterior wall ratio; $E S D$, endsystolic dimension; \% IVS, septal systolic thickening; LVPW ex, left ventricular posterior wall excursion; IVS amp-C, ventricular septal amplitude of motion at chordal level; IVS amp- $M$, ventricular septal amplitude of motion just below mitral valve level.

lectrocardiographic monitoring. All of these 26 patients had undergone cardiac catheterisation within the three years before this study and were on beta-adrenergic blocking drugs (range in propranolol equivalents: 60 to $800 \mathrm{mg}$, mean: 260 $\mathrm{mg} /$ day) when they were studied by echocardiography.

Fifteen patients were men and 11 were women. The mean age was 48 years (age range: 21 to 71 ). Twenty-one of the patients were in sinus rhythm and five in established atrial fibrillation. Twelve of the patients complained of palpitation and six of these patients had had at least one previous episode of syncope.

Left ventricular, mitral valve leaflet, aortic root, and left atrial echocardiograms and continuous sweep recordings of the ventricular septum from the base of the heart toward the apex were obtained by standard methods. ${ }^{4}$ Ekoline 20 Ultrasonoscope was used with a $2.25 \mathrm{MHz}$ transducer and a repetition frequency of 1000 pulses/s. The output was displayed on the Cambridge strip chart recorder with a simultaneous electrocardiogram. Studies were made with patients in the supine or slight left lateral position, with the transducer at the left sternal edge.

The following echocardiographic features were assessed (Fig. 1 and 2): (1) ventricular septal amplitude of motion; (2) ventricular systolic septal thickening; (3) ventricular septal thickness at end-
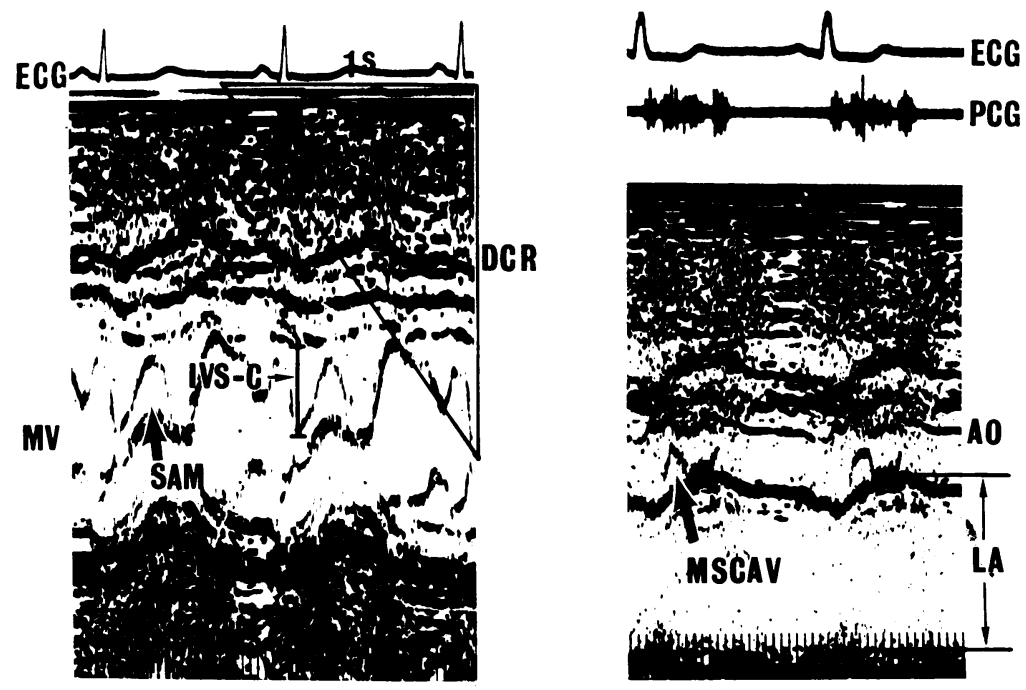

Fig. 2 The echocardiographic features assessed. $M V$, mitral valve; IVS-C, septal mitral valve distance at the onset of systole; $S A M$, systolic anterior movement of the mitral valve; $D C R$, diastolic closure rate of the anterior mitral valve; $M S C A V$, mid-systolic closure of the aortic valve; $A O$, aortic root; $L A$, left atrial dimension. 
PATTERN OF VENTRICULAR SEPTAL MOTION

Fig. 3 Six types of septal motion. $N$, normal septal motion (amplitude of motion $>5 \mathrm{~mm}$ ); $R$, reduced septal motion ( 5 to $3 \mathrm{~mm}) ; F$, flat septal motion (2 to $0 \mathrm{~mm}$ ); $P$, paradoxical septal motion; $M V$, mitral valve; IVS, ventricular septum; "Flat" (at MV level) + "paradoxical" (at chordal level) is theoretically possible but not detected in these 26 patients.

\begin{tabular}{|c|l|l|}
\hline TYPE & $\begin{array}{c}\text { Just below (or at) } \\
\text { MV level }\end{array}$ & $\begin{array}{l}\text { At } \\
\text { Chordal level }\end{array}$ \\
\hline I & Normal & Normal \\
\hline II & Reduced & Normal \\
\hline III & Reduced & Reduced \\
\hline IV & Flat & Reduced \\
\hline V & Flat & Flat \\
\hline VI & Paradoxical & Paradoxical \\
\hline
\end{tabular}

diastole; (4) ventricular septal thickness to left ventricular posterior wall ratio; (5) left ventricular posterior wall excursion; (6) left ventricular endsystolic dimension; (7) septal mitral valve distance at the onset of systole; (8) diastolic closure rate of the anterior mitral valve leaflet; (9) systolic anterior movement of the mitral valve; (10) mid-systolic closure of the aortic valve; (11) left atrial dimension at end-systole. Ventricular septal amplitude of motion (Fig. 1) was assessed just below (or at) the plane of the mitral valve and at chordal level by continuous sweep recording of the ventricular septum from the base toward the apex, and the pattern of septal motion seen was classified into six types based on normal, reduced, flat, or paradoxical septal motion (Fig. 3). Features (2) to (6) were assessed from the echocardiograms obtained just below the plane of the mitral valve, where the minor axis of the left ventricle was recorded (Fig. 1). Feature (2) septal systolic thickening was expressed as systolic thickness minus diastolic thickness divided by diastolic thickness (S-D/D). Features (7) to (9) were assessed from the echocardiograms obtained at the plane of the mitral valve tip where both anterior and posterior leaflets were recorded simultaneously (Fig. 2). Features (10) and (11) were assessed from the echocardiograms obtained at the plane of the aortic root and the left atrium where both anterior and posterior aortic cusps were visualised (Fig. 2).

The arrhythmias detected have been reported elsewhere. ${ }^{2}$ The frequency of ventricular tachycardia was almost identical with or without betaadrenergic blocking drugs. For the purpose of this study the patients were grouped according to the most serious ventricular arrhythmia present with or without beta-adrenergic blocking drugs: group (A) ventricular tachycardia defined as three or more

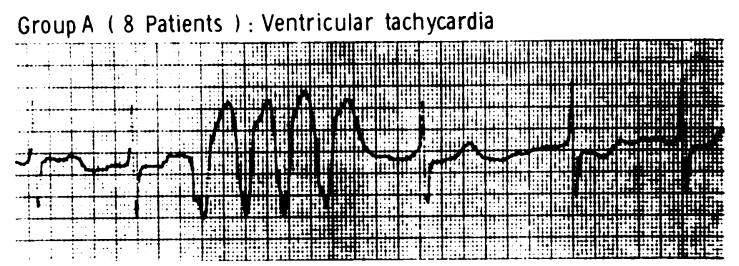

Group B (II Patients ): Multiform or paired VES

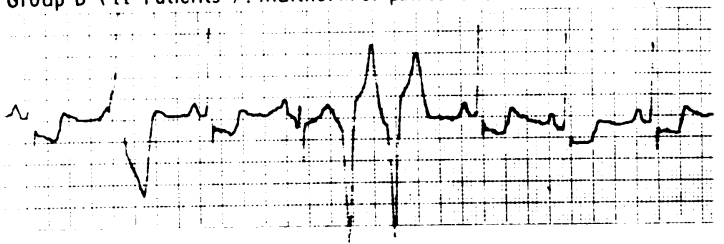

Group C ( 7 Patients ) : Uniform VES

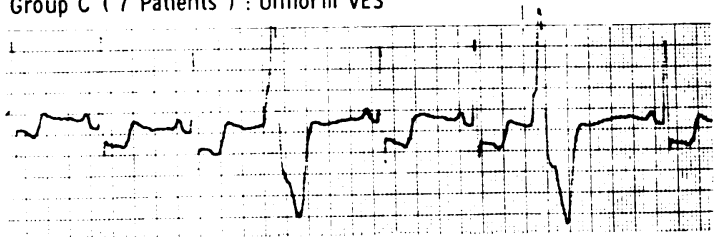

Fig. 4 Representative ambulatory electrocardiograms in three groups of patients. VES, ventricular extrasystoles. 
ventricular extrasystoles in succession, eight patients; group (B) multiform or paired ventricular extrasystoles, 11 patients; group (C) uniform ventricular extrasystoles, seven patients (Fig. 4). In group (C), five patients had fewer than 30 ventricular extrasystoles an hour and two patients had more than 30 ventricular extrasystoles an hour. The echocardiographic features assessed were compared in these groups.

Standard statistical analyses were performed. The difference between two proportions was examined using the Fisher's exact test. One-way analysis of variance was performed initially to test the difference between means of more than two groups and this was followed by a two-sample $t$ test when the result was significant.

\section{Results}

Results are shown in the Table.

Mean ventricular septal amplitude of motion at chordal level was $4.0 \pm 0.9$ (standard error of the mean) $\mathrm{mm}$ in group $\mathrm{A}, 5.5 \pm 0.4 \mathrm{~mm}$ in group $B$, and $7 \cdot 0 \pm 0.6 \mathrm{~mm}$ in group $C$, and there was $a$ significant difference between group $A$ and $C$ $(p=0.017)$, group $B$ and $C(p=0.042)$, and group
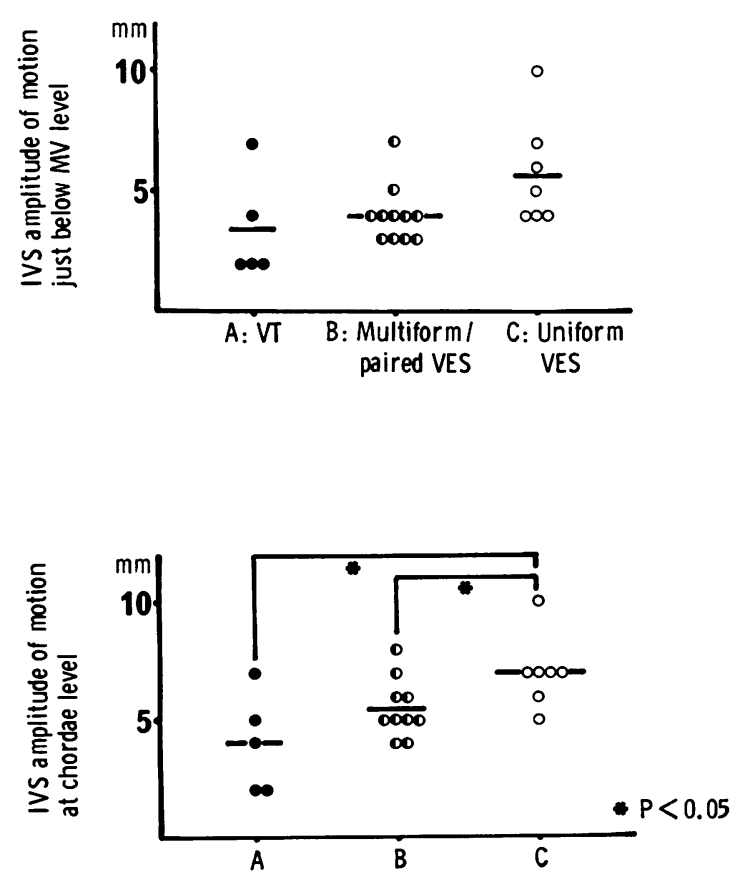

Fig. 5 Ventricular septal amplitude of motion. IVS, ventricular septum; $M V$, mitral valve; $V T$, ventricular tachycardia; VES, ventricular extrasystoles.

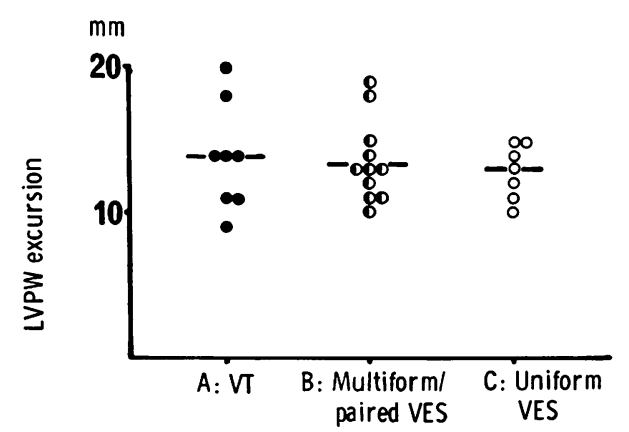

$A+B$ and $C(p=0 \cdot 015)$, but no significant difference between group A and B (Fig. 5).

Mean septal systolic thickening was $11.6 \pm 3.0$ per cent in group A, 13.6 \pm 1.8 per cent in group $B$, and $22.9 \pm 1.9$ per cent in group $C$. There was significant difference between group $A$ and $C$, group $B$ and $C$, and group $A+B$ and $C(p<0.01$ for each), but no significant difference between group A and B (Fig. 6). Mean ventricular septal amplitude of motion just below the mitral valve level, left ventricular posterior wall excursion, ventricular septal thickness, or ventricular septal thickness to posterior wall ratio did not show any significant difference in these three groups of patients.

Within each group systolic anterior movement of the mitral valve and mid-systolic closure of the aortic valve were detected with identical frequency: two patients $(25 \%)$ in group $A$, seven patients $(64 \%)$ in group $B$, and six patients $(86 \%)$ in group $\mathrm{C}$, and there was a significant difference between group $A$ and $C(p<0.05)$ (Fig. 7).

Six different patterns of septal motion were derived from the amplitude of septal motion at two different levels: just below the plane of the mitral 
valve and at chordal level. In group $A$, six of eight patients $(75 \%)$ showed type IV, V, or VI. In group $\mathrm{B}$, seven of 11 patients $(64 \%)$ showed type III. In group $\mathrm{C}$, six of seven patients $(86 \%)$ showed type I or II (Fig. 3 and 8).

Three patients had paradoxical septal motion (type VI), and since completion of the study two of them have died. Case 1 was diagnosed in 1973. $\mathrm{He}$ was in left ventricular failure, on digitalis and diuretics, and died suddenly. His echocardiogram showed paradoxical septal motion and decreased septal systolic thickening. Case 2 was operated on in 1958 and was the first patient to be treated surgically. Apart from a syncopal episode, he was in controlled left ventricular failure, but died suddenly while watching television. His electrocardiogram showed left bundle-branch block and his echocardiogram showed a grossly thickened septum with paradoxical septal motion and reduced septal systolic thickening. He was the only patient in the study with bundle-branch block. The other two patients with paradoxical septal motion had no clinical or echocardiographic evidence of other causes of paradoxical septal motion.

\section{Discussion}

None of the classical echocardiographic features of hypertrophic cardiomyopathy was predictive of serious ventricular arrhythmia, except ventricular septal amplitude of motion and septal systolic thickening. Though the echocardiographic features of obstruction, systolic anterior movement of the mitral valve and mid-systolic closure of the aortic valve, ${ }^{5-7}$ had previously been positively associated with ventricular arrhythmia, ${ }^{8}$ we found the oppo-

Table Echocardiographic data in group $A:$ ventricular tachycardia in group $B:$ multiform or paired ventricular extrasystoles $\stackrel{\bar{\oplus}}{+}$ and in group $C$ : uniform ventricular extrasystoles

\begin{tabular}{|c|c|c|c|c|c|c|c|c|c|c|c|c|c|}
\hline \multirow[b]{2}{*}{$\begin{array}{l}\text { Case } \\
\text { no. }\end{array}$} & \multirow{2}{*}{ Sex } & \multirow{2}{*}{ Age (y) } & \multirow{2}{*}{$\begin{array}{l}\text { Pattern of } \\
\text { IVS motion }\end{array}$} & \multicolumn{2}{|c|}{ IVS amplitude ( $\mathrm{mm}$ ) } & \multirow[b]{2}{*}{$\begin{array}{l}\text { IVS } \\
\text { systolic } \\
\text { thickening } \\
\left(\begin{array}{l}0 \\
0\end{array}\right)\end{array}$} & \multirow[b]{2}{*}{$\begin{array}{l}\text { IVS } \\
\text { thickness } \\
(\mathrm{mm})\end{array}$} & \multirow[b]{2}{*}{$\begin{array}{l}\text { IVS } \\
\text { LVPW } \\
\text { ratio }\end{array}$} & \multirow[b]{2}{*}{$\begin{array}{l}\text { LVPW } \\
\text { excursion } \\
(\mathrm{mm})\end{array}$} & \multirow[b]{2}{*}{$\begin{array}{l}\text { LVESD } \\
(\mathrm{mm})\end{array}$} & \multirow[b]{2}{*}{$\begin{array}{l}I V S-C \\
(\mathrm{~mm})\end{array}$} & \multirow[b]{2}{*}{$\begin{array}{l}D C R \\
(\mathrm{~mm} / \mathrm{s})\end{array}$} & \\
\hline & & & & $\begin{array}{l}\text { Flist below } \\
M V \text { level }\end{array}$ & $\begin{array}{l}\text { At } \\
\text { chordae } \\
\text { level }\end{array}$ & & & & & & & & 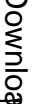 \\
\hline \multicolumn{13}{|l|}{ Group $A$} & \\
\hline 1 & $M$ & 59 & VI & $(\mathrm{P})$ & $(\mathrm{P})$ & 14 & 19 & 1.9 & 11 & 43 & 19 & 43 & อ르 \\
\hline 2 & $M$ & 62 & VI & (P) & (P) & 2 & 29 & $4 \cdot 8$ & 14 & 24 & 10 & 22 & - \\
\hline 3 & $M$ & 44 & VI & (P) & $(\mathrm{P})$ & 9 & 20 & 2.5 & 18 & 30 & 32 & 60 & 으 \\
\hline 4 & $M$ & 49 & III & 4 & 4 & 19 & 22 & $2 \cdot 2$ & 9 & 26 & 19 & 16 & 3 \\
\hline 5 & $\mathrm{M}$ & 56 & $\mathrm{~V}$ & 2 & 2 & 3 & 29 & 3.6 & 14 & 34 & 27 & 136 & $\tau$ \\
\hline 6 & $\mathrm{~F}$ & 57 & I & 7 & 7 & 25 & 14 & 1.6 & 11 & 21 & 21 & 91 & 言 \\
\hline 7 & $F$ & 37 & IV & 2 & 5 & 17 & 20 & 1.6 & 14 & 17 & 27 & 58 & C \\
\hline 8 & $M$ & 37 & $\mathrm{~V}$ & 2 & 2 & 4 & 27 & 1.9 & 20 & 18 & 25 & 19 & 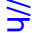 \\
\hline Mean & & & & $3 \cdot 4$ & $4 \cdot 0$ & $11 \cdot 6$ & 22.5 & $2 \cdot 5$ & 13.9 & $26 \cdot 6$ & $22 \cdot 5$ & 55.0 & $\vec{D}$ \\
\hline \pm SEM & & & & $\pm 1 \cdot 0$ & \pm 0.9 & \pm 3.0 & $\pm 1 \cdot 9$ & \pm 0.4 & $\pm 1 \cdot 3$ & $\pm 3 \cdot 1$ & $\pm 2 \cdot 4$ & $\pm 14 \cdot 6$ & \\
\hline \multicolumn{13}{|l|}{ Group B } & 7 \\
\hline 9 & $\mathbf{M}$ & 23 & & 3 & - & 9 & 11 & $1 \cdot 6$ & 11 & 36 & 23 & 72 & \\
\hline 10 & $\mathbf{F}$ & 57 & III & 4 & 5 & 8 & 25 & 1.0 & 11 & 21 & 19 & 16 & \\
\hline 11 & $\mathrm{M}$ & 35 & I & 7 & 7 & 20 & 15 & 0.9 & 15 & 17 & 22 & 17 & \\
\hline 12 & $\mathbf{M}$ & 44 & II & 5 & 6 & 15 & 20 & $1 \cdot 8$ & 10 & 25 & 26 & 30 & $\supsetneq$ \\
\hline 13 & $\mathrm{M}$ & 58 & III & 4 & 4 & 10 & 22 & 1.7 & 13 & 27 & 24 & 41 & 0 \\
\hline 14 & $\mathrm{~F}$ & 60 & II & 4 & 6 & 15 & 23 & $2 \cdot 3$ & 12 & 19 & 19 & 35 & כ \\
\hline 15 & $\mathrm{~F}$ & 59 & III & 4 & 4 & 5 & 23 & $2 \cdot 3$ & 19 & 31 & 22 & 74 & $D$ \\
\hline 16 & $\mathrm{~F}$ & 71 & III & 3 & 5 & 14 & 20 & 1.8 & 13 & 26 & 24 & 88 & \\
\hline 17 & $M$ & 32 & III & 3 & 5 & 26 & 17 & 1.9 & 14 & 14 & 19 & 21 & \\
\hline 18 & $\mathbf{M}$ & 43 & III & 3 & 5 & 16 & 21 & $2 \cdot 6$ & 18 & 22 & 24 & 45 & Tu \\
\hline 19 & $F$ & 55 & II & 4 & 8 & 12 & 17 & 1.9 & 13 & 24 & 27 & 51 & $\sigma$ \\
\hline Mean & & & & 4.0 & $5 \cdot 5$ & 13.6 & $19 \cdot 5$ & 1.8 & 13.6 & $23 \cdot 8$ & $22 \cdot 6$ & $44 \cdot 6$ & N \\
\hline \pm SEM & & & & \pm 0.4 & \pm 0.4 & $\pm 1 \cdot 8$ & $\pm 1 \cdot 2$ & $\pm 0 \cdot 2$ & \pm 0.9 & \pm 1.9 & $\pm 0 \cdot 8$ & $\pm 7 \cdot 4$ & \\
\hline \multicolumn{14}{|l|}{ Group $C$} \\
\hline 20 & $\mathrm{~F}$ & 51 & II & 4 & 7 & 24 & 19 & $2 \cdot 7$ & 11 & 21 & 15 & - & \\
\hline 21 & $\mathrm{M}$ & 60 & I & 7 & 7 & 24 & 28 & $3 \cdot 1$ & 14 & 24 & 25 & 0 & 으 \\
\hline 22 & $\mathrm{~F}$ & 59 & III & 4 & 5 & 14 & 20 & $2 \cdot 2$ & 15 & 24 & 25 & 35 & $\frac{c}{\Phi}$ \\
\hline 23 & $M$ & 48 & I & 10 & 10 & 20 & 27 & $1 \cdot 4$ & 13 & 19 & 25 & 13 & D \\
\hline 24 & $M$ & 44 & I & 6 & 7 & 23 & 15 & $1 \cdot 4$ & 12 & 24 & 18 & 183 & \\
\hline 25 & $\mathrm{~F}$ & 31 & II & 5 & 7 & 30 & 21 & 1.9 & 15 & 26 & 18 & 0 & T \\
\hline 26 & $\mathrm{~F}$ & 21 & II & 4 & 6 & 25 & 12 & $1 \cdot 3$ & 10 & 29 & 31 & 63 & $\overline{0}$ \\
\hline $\begin{array}{l}\text { Mean } \\
\pm \text { SEM }\end{array}$ & & & & $\begin{array}{r}5.7 \\
\pm 0.8\end{array}$ & $\begin{array}{r}7.0 \\
\pm 0.6\end{array}$ & $\begin{array}{r}22.9 \\
\pm 1.9\end{array}$ & $\begin{array}{l}20 \cdot 3 \\
\pm 2 \cdot 2\end{array}$ & $\begin{array}{r}2.0 \\
\pm 0.3\end{array}$ & $\begin{array}{l}12.9 \\
\pm 0.7\end{array}$ & $\begin{array}{r}23.9 \\
\pm 1.2\end{array}$ & $\begin{array}{l}22 \cdot 4 \\
\pm 2 \cdot 1\end{array}$ & $\begin{array}{r}49 \cdot 0 \\
\pm 28.6\end{array}$ & 蛋 \\
\hline
\end{tabular}

IVS, interventricular septum; MV, mitral valve; LVPW, left ventricular posterior wall; ESD, end-systolic dimension; IVS-C, septal-mitral valve distance; DCR, diastolic closure rate of the mitral valve; SAM, systolic anterior movement of the mitral valve; MSCAV, mid-systolic closure of the aortic valve; LA, left atrium; (P), paradoxical septal motion; LBBB, left bundle-branch block; SR, sinus rhythm; AF, atrial fibrillation; LVH, left ventricular hypertrophy EDP, end-diastolic pressure; NON, non-obstructive; L, labile obstructive; R, resting obstructive. 
site. In our study the presence of systolic anterior movement of the mitral valve and/or mid-systolic closure of the aortic valve were inversely correlated with ventricular tachycardia (Fig. 7). This is consistent with our natural history study in which an overall worse prognosis was found in the patient who had no resting or provokable gradient at the follow-up haemodynamic study. ${ }^{9}$

It has been previously postulated that loss of outflow tract obstruction may be associated with impairment of contractile function and may indicate progression of the disease. ${ }^{10}$ This concept was supported by previous histological studies where the typical findings of the alteration in the shape of the muscle cells and the abnormalities of myofibrillar structure and orientation are present in the ventricular septum, ${ }^{11}$ but are either absent or rarely found in muscle from the left and right ventricular
SAM \& MSCAV

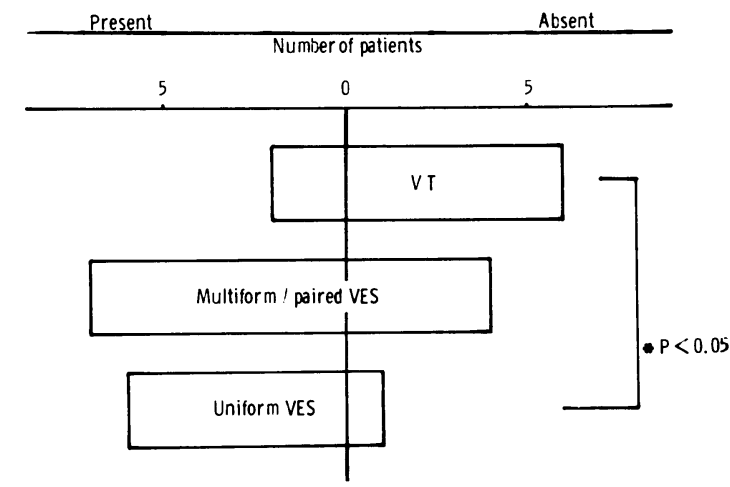

Fig. 7 Systolic anterior movement of the mitral valve (SAM) and mid-systolic closure of the aortic valve (MSCAV). VT, ventricular tachycardia; VES, ventricular extrasystoles.

free walls in the patients with obstruction. In contrast, many abnormal cells were extensively present in the left and right ventricular free walls in seven of eight patients without obstruction, ${ }^{12}$ suggesting that extensive involvement of the free walls of the ventricles as well as the septum is limited to the patients without obstruction. Our result that echocardiographic features of obstruction were inversely correlated with ventricular tachycardia and risk of sudden death fits in with this concept that patients with gradients have more circumscribed and less widespread disease than those without obstruction.

In this study there was no correlation between serious ventricular arrhythmia and ventricular

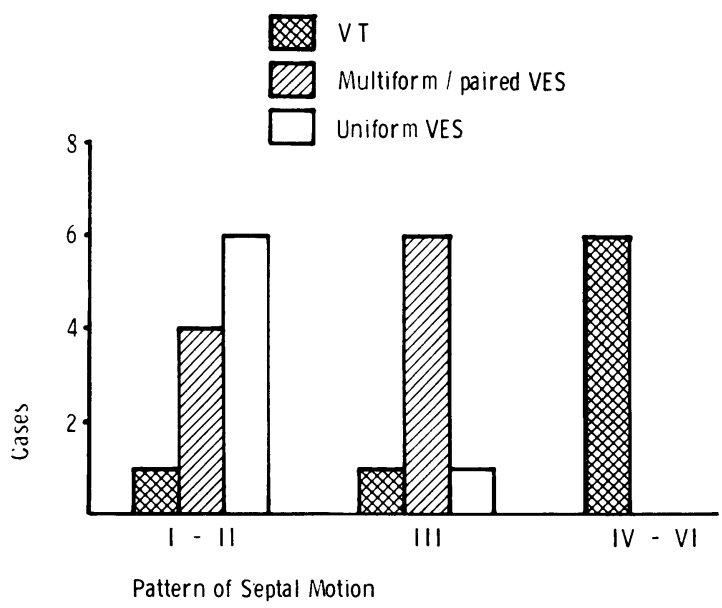

Fig. 8 Type of septal motion seen in the three groups of patients. VT, ventricular tachycardia; VES, ventricular extrasystoles. 
septal thickness. Ventricular septal systolic thickening just below the plane of the mitral valve and the septal amplitude of motion at chordal level best correlated, however, with serious ventricular arrhythmia. Assessment of the ventricular septal amplitude of motion at one level can provide only limited information about the overall function and degree of involvement of the ventricular septum. The changes in septal motion at different levels in hypertrophic cardiomyopathy recorded by a continuous sweep from the base towards the apex have previously been demonstrated. ${ }^{13}$ The septal amplitude of motion and systolic septal thickening have been studied by several investigators, ${ }^{13-15}$ but none has previously attempted to assess septal motion at different levels. Histologically, the ventricular septum is the part of the heart which is most frequently involved and which shows the most severe changes and that is why we examined the whole length of the septum in order to describe its function in toto and not just at one site. The septal amplitude of motion was measured just below mitral valve level and at chordal level. Six different patterns of septal motion could be described (Fig. 3 and 8): 86 per cent of patients without serious ventricular arrhythmia showed normal (type I) or nearly normal (type II) patterns of septal motion, whereas severely impaired septal motion at both levels (type IV, V, and VI) was present in 75 per cent of the patients with ventricular tachycardia; 64 per cent of patients with serious ventricular arrhythmia showed moderately impaired septal motion (type III).

Paradoxical septal motion (type VI) appears to indicate the most severe form of ventricular septal dysfunction. It was found only in three patients; two have died suddenly and all three had ventricular tachycardia (Table: cases 1 to 3). The echocardiograms of the patients with ventricular tachycardia showed features of severity; (1) decreased septal amplitude of motion or paradoxical motion progressively along the septum from the base toward the apex; (2) conspicuously decreased septal systolic thickening.

Precise electrophysiological studies on these patients have not been performed and we are unable to determine the origin of the ventricular tachycardia from ambulatory electrocardiographic monitoring. Theoretically, extensive involvement of the ventricular septum by the myopathic process will provide an ideal locale for the initiation of re-entry circuits, but this remains to be investigated.

In conclusion, two indicators of ventricular septal function, amplitude of motion at chordal level and septal systolic thickening, best predicted serious ventricular arrhythmia. Two of three patients who had paradoxical septal motion died suddenly, but because of the presence of possible other explanations for paradoxical septal motion we hesitated to emphasise this correlation between paradoxical septal motion and sudden death. Additional information was obtained by a continuous sweep recording of the septum from the base toward the apex. This provided further assessment of septal function. The echocardiographic features of obstruction, systolic anterior movement of the mitral valve and mid-systolic closure of the aortic valve, were inversely correlated with ventricular tachycardia.

This work was carried out with the aid of a grant from the British Heart Foundation.

\section{References}

1 Hardarson T, De La Calzada CS, Curiel R, Goodwin JF. Prognosis and mortality of hypertrophic obstructive cardiomyopathy. Lancet 1973; ii: 1462-7.

2 McKenna WJ, Chetty S, Oakley CM, Goodwin JF. Arrythmia in hypertrophic cardiomyopathy: exercise and 48 hour ambulatory electrocardiographic assessment with and without beta adrenergic blocking therapy. Am f Cardiol 1980; 45: 1-5.

3 Maron BJ, Roberts WC, Edwards JE, McAllister HA, Foley DD, Epstein SE. Sudden death in patients with hypertrophic cardiomyopathy: characterisation of 26 patients without functional limitation. $A m \mathcal{F}$ Cardiol 1978; 41: 803-10.

4 Feigenbaum H. Clinical application of echocardiography. Progr Cardiovasc Dis 1972; 14: 531-58.

5 Shah PM, Gramiak R, Kramer DH. Ultrasound localization of left ventricular outflow obstruction in hypertrophic obstructive cardiomyopathy. Circulation 1969; 40: 3-11.

6 Gramiak R, Shah PM, Kramer DH. Ultrasound cardiology; contrast studies in anatomy and function. Radiology 1969; 92: 939-48.

7 Doi YL, McKenna WJ, Gehrke J, Oakley CM, Goodwin JF. M-mode echocardiography in hypertrophic cardiomyopathy; diagnostic criteria and prediction of obstruction. Am $\mathcal{F}$ Cardiol 1980; 45: 6-14.

8 Lever HM, Shah PM, Reeves WC, Nanda NC, Gramiak $R$. The relation of left ventricular outflow obstruction to ventricular arrhythmias in hypertrophic subaortic stenosis (abstract). Circulation 1976; 53 \& 54, suppl II: 105.

9 McKenna WJ, Deanfield J, Oakley CM, Goodwin JF. Prognosis and mortality in hypertrophic cardiomyopathy (abstract). Circulation 1979; 59 \& 60, suppl II : 164.

10 Goodwin JF, ? IHSS, ? HOCM, ? ASH. A plea for unity. Am Heart $\mathcal{F} 1975 ; 89: 269-77$.

11 Ferrans VJ, Morrow AG, Roberts WC. Myocardial ultrastructure in idiopathic hypertrophic subaortic stenosis; study of operatively excised left ventricular 
outflow tract muscle in 14 patients. Circulation 1972; 45: 769-92.

12 Maron BJ, Ferrans VJ, Hentry WL, et al. Differences in distribution of myocardial abnormalities in patients with obstructive and nonobstructive asymmetric septal hypertrophy (ASH); light and electron microscopic findings. Circulation 1974; 50: 436-46.

13 Tajik AJ, Giuliani ER. Echocardiographic observations in idiopathic hypertrophic subaortic stenosis. Mayo Clin Proc 1974; 49: 89-97.

14 Rossen RM, Goodman DJ, Ingham RE, Popp RL. Ventricular systolic septal thickening and excursion in idiopathic hypertrophic subaortic stenosis. $N$ Engl f Med 1974; 291 : 1317-9.

15 Cohen MV, Cooperman LB, Rosenblum R. Regional myocardial function in idiopathic hypertrophic subaortic stenosis; an echocardiographic study. Circulation 1975; 52: 842-7.

Request for reprints to Dr Yoshinori L Doi, The Third Division, Department of Medicine, Osaka Medical College, 2-7 Daigaku-cho, Takatsuki-city, Osaka 569, Japan. 